\title{
Effect of male presence and of photoperiod on the sexual maturation of the field vole (Microtus agrestis)
}

\author{
Norah Spears* and J. R. Clarke* \\ Department of Agricultural Science, University of Oxford, Parks Road, Oxford OX1 3PF, U.K.
}

\begin{abstract}
Summary. The effect of mature males on the sexual development of young female and male field voles, reared in either long (stimulating) or short (inhibiting) photoperiods, was examined. Females reared in the presence of a mature male had a more advanced state of sexual maturation (as indicated by uterine weight) than did females reared in isolation from males, in long and short photoperiods $(P<0.01)$. No interaction between photoperiod and male presence was found. Augmented uterine growth occurred not only when young females were separated from mature males by a wire mesh or solid metal screen but also when they were merely exposed to bedding previously used by mature males. Castrated males had no effect on the sexual development of females. The effect of mature males on the sexual development of young males was less clear, although there was some indication that the presence of adult males inhibited their sexual development in long and short photoperiods. For males and females, growth rate was stimulated by long photoperiod, but no effect of male presence on growth rate was found.
\end{abstract}

\section{Introduction}

Photoperiod is the principal environmental factor controlling sexual development in the field vole (Microtus agrestis): long photoperiods accelerate and short photoperiods retard or inhibit sexual development (Baker \& Ranson, 1933; Clarke \& Kennedy, 1967; Grocock \& Clarke, 1974). However, there are reasons for supposing that the effect of photoperiod may be modified by other environmental features, including social factors (Clarke \& Kennedy, 1967; Clarke, 1981). In a limited experiment, it has already been demonstrated that vaginal perforation of weaned female field voles is hastened when they are in permanent direct contact with sexually mature males (Clarke \& Clulow, 1973). This acceleration of puberty seen in females reared in the presence of mature males has been noted in a wide range of mammal species, particularly amongst rodents (for review, see Marchlewska$\mathrm{Koj}, 1984)$. On the other hand, sexual maturation of male laboratory mice and laboratory-bred bank voles is delayed by the presence of conspecific sexually mature males (Vandenbergh, 1971; Gustafsson, 1983).

Here, we report the results of experiments designed to study more closely the effect of mature males upon the sexual development of young female and male field voles, reared in long or short photoperiods, examining the separate and joint effect of photoperiod and male presence.

\section{Materials and Methods}

Animals. All animals were from the field vole colony maintained in the Department of Agricultural Science, Oxford, on a photoperiodic regimen of $16 \mathrm{~h}$ light:8 h dark (16L:8D) (Baker \& Clarke, 1986). They were fed oats and Dixon's diet 41 B ad libitum, supplemented twice weekly by carrots and hay. Water was constantly available. The experimental animals, which were weanlings

\footnotetext{
* Present address: Department of Zoology, University of Oxford, South Parks Road, Oxford OX1 3PS, U.K.
} 
when treatments began, were housed in wire mesh cages $(28 \times 18 \times 12 \mathrm{~cm})$, divided down the middle by a screen of wire mesh (holes $7 \times 7 \mathrm{~mm}$ ) or of solid metal. Two weanling voles (aged $16 \pm 1$ days) were placed in one half of each cage. In treatments in which the experimental animals were exposed to adult males (intact or castrated) each adult male was housed in the other half of a cage. The barrier allowed only slight tactile contact between the adult males and the experimental animals, which were exposed to a different adult male each week. No adult male was placed in short photoperiod for longer than 7 days at a time. This ensured, in the intact males, that regression of the testes did not occur (Clarke \& Kennedy, 1967; Grocock, 1972). When young females were exposed to soiled bedding, this was placed with the females in one half of the divided cages.

Animals were kept in photoperiod cabinets (Grocock \& Clarke, 1974) in rooms without other mature males or females. These cabinets were equipped with four $25-\mathrm{W}$ tungsten bulbs, giving a light intensity of $188.3 \mathrm{klx}$ at the front of the cage and $27.2 \mathrm{klx}$ in the nest. Temperature in the cabinets was $18 \pm 2^{\circ} \mathrm{C}$.

In all 4 experiments, treatments continued for 6 weeks. Animals were then killed by ether vapour. Ovaries, uteri, testes and pituitary glands were weighed fresh and fixed in Bouin's fluid. Carcasses of males were preserved in $10 \%$ formalin, and the seminal vesicles were later weighed. Paraffin wax sections $(6 \mu \mathrm{m})$ of ovaries and testes were stained with Ehrlich's haematoxylin and eosin.

Experiment 1. Treatments were arranged as a $2 \times 2$ factorial (Bailey, 1981) with females reared in long photoperiod (LP: 16L:8D) or short photoperiod (SP: 6L:18D), and in the presence (+ $\left.\delta^{*}\right)$ or absence $\left(-\delta^{\star}\right)$ of a sexually mature male. Groups of 4 weanling females, matched for age, body weight and absence of sexual development, were assigned to one of the four treatments $\left(\mathrm{LP}+\sigma^{\hat{}}\right.$, $\mathbf{L P}-\hat{\sigma}, \mathbf{S P}+\delta, \mathrm{SP}-\delta)$. There were 6 such blocks of 4 comparable animals.

Experiment 2. Groups of 4 weanling females, matched for age, body weight and absence of sexual development, were placed in a short photoperiod (6L:18D) and assigned to one of th? following treatments:

T1: separated from a mature male by a wire mesh barrier (as in Exp. 1);

T2: separated from a mature male by a double wire-mesh barrier, allowing no tactile contact between the animals;

T3: separated from a mature male by a solid metal sheet, allowing neither tactile nor visual contact between the animals;

T4: in a room isolated from any males, but reared in bedding that had immediately before this been used by 4 or 5 mature male voles, living together in a wire mesh cage. The used bedding was replaced twice weekly.

Experiment 3. Weanling females, arranged as 6 pairs of comparable animals, were allocated at random to one of two treatments in a short photoperiod (6L:18D):

(a) separated by a wire mesh barrier from a sexually mature male $(\mathrm{SP}+\delta)$ or

(b) separated by a wire mesh barrier from a castrated male $\left(\mathrm{SP}+\phi^{*}\right)$. These males had been castrated at least 4 weeks before the start of the experiment, to ensure that their accessory sexual organs had fully regressed (Jorné-Safriel, 1968).

Experiment 4. Using a $2 \times 2$ factorial design, males were reared in long photoperiod (LP: 16L:8D) or short photoperiod (SP: 6L:18D), and in the presence $\left(+{ }^{\star}\right)$ or absence $\left(-\sigma^{*}\right)$ of a sexually mature male. Groups of 4 weanling males, matched for age, body weight and absence of sexual development, were assigned at random to the four treatments $(\mathrm{LP}+\hat{\delta}, \mathbf{L P}-\hat{\delta}, \mathbf{S P}+\delta$, SP $-\delta$ ). There were 7 such blocks of 4 animals.

The width of the seminiferous tubules was estimated by measuring 15 tubules in each animal, and using the average of these figures as the best estimate for each vole.

Growth rates. In all experiments, growth rates were calculated from the difference between final and initial body weights divided by time in days. 
Statistics. The significance of effects of treatments was tested by a Factorial Analysis of Variance (Bailey, 1981).

\section{Results}

\section{Experiment 1: the effect of photoperiod and male presence on female maturation}

Uteri increased in weight in the order SP $-\hat{\jmath}, \mathrm{SP}+\hat{\jmath}, \mathrm{LP}-\hat{\jmath}$, to LP $+\hat{\jmath}$ (see Fig. 1). Analysis of variance showed a significant photoperiod $(P<0.001)$ and male $(P<0.01)$ effect, but no interaction between the two factors. Uterine weights were more variable in the SP $+\delta$ treatment than in others, as shown by the coefficients of variation. Weights ranged from 8.4 to $51.7 \mathrm{mg}$. However, neither in this nor in any other experiments was there significant heterogeneity of variances.

Ovarian and pituitary gland weights showed the same pattern of treatment differences (see Table 1). There was a significant photoperiod effect on ovarian and pituitary weights $(P<0.001$ for both), and a significant male effect on pituitary weights only $(P<0.05)$. In no case was any interactive effect found.

Growth rates were significantly higher in long than in short photoperiods $(P<0.01)$ but were not affected by the presence of a male (Table 2).

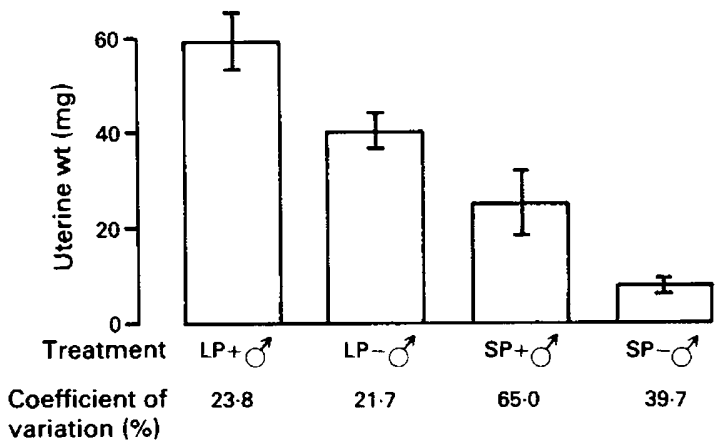

Fig. 1. Uterus weights (mean \pm s.e.m., 6 animals per treatment) for females in Exp. 1, which were exposed for 6 weeks to long (LP) or short (SP) photoperiods in the presence $(+\delta)$ or absence $(-\delta)$ of a sexually mature male.

Table 1. Ovary and pituitary gland weights (mg) for females in Exp. 1, exposed for 6 weeks to long (LP) or short (SP) photoperiods, in the presence $(+\hbar)$ or absence $\left(-\sigma^{\star}\right)$ of a sexually mature male

\begin{tabular}{|c|c|c|c|c|c|c|}
\hline & \multicolumn{4}{|c|}{ Treatment } & \multirow{2}{*}{$\begin{array}{c}\text { Photoperiod } \\
\text { effect }\end{array}$} & \multirow{2}{*}{$\begin{array}{l}\text { Male } \\
\text { effect }\end{array}$} \\
\hline & $\mathbf{L P}+\hat{\sigma}$ & $\mathbf{L P}-\hat{\sigma}$ & $\mathbf{S P}+a$ & $\mathbf{S P}-\vec{a}$ & & \\
\hline $\begin{array}{l}\text { Wt of ovaries } \\
\text { Wt of pituitary }\end{array}$ & $\begin{array}{l}5.73 \pm 0.51 \\
2.33 \pm 0.24\end{array}$ & $\begin{array}{l}4.65 \pm 0.33 \\
1.68 \pm 0.18\end{array}$ & $\begin{array}{l}2 \cdot 85 \pm 0.35 \\
1 \cdot 18 \pm 0 \cdot 10\end{array}$ & $\begin{array}{l}2.22 \pm 0.26 \\
0.92 \pm 0.09\end{array}$ & $\begin{array}{l}P<0.001 \\
P<0.001\end{array}$ & $\begin{array}{c}\text { n.s. } \\
P<0.05\end{array}$ \\
\hline
\end{tabular}

Values are mean \pm s.e.m.; 6 animals per treatment.

\section{Experiment 2: nature of the male stimulus}

There was no treatment effect on uterine weights (see Fig. 2). Uterine weights in these treatments were not significantly different from those in Exp. 1, treatment SP $+\delta$. As with that treatment, all uteri were significantly heavier than those of females in Exp. 1, treatment SP $-\sigma$. The coefficient of variation was large in all four treatments.

There was no treatment effect on growth rates. 
Table 2. Growth rates (g/day) of animals in Exp. 1 (6 animals per treatment) and Exp. 4 (7 animals per treatment) exposed for 6 weeks to long (LP) or short (SP) photoperiods in the presence $(+\delta)$ or absence $\left(-\delta^{*}\right)$ of a sexually mature male

\begin{tabular}{lcccccc}
\hline & \multicolumn{4}{c}{ Treatment } & Photoperiod & Male \\
& \cline { 2 - 5 } & effect & effect \\
\hline Females in Exp. 1 & $0.39 \pm 0.03$ & $0.43 \pm 0.03$ & $0.34 \pm 0.03$ & $0.30 \pm 0.02$ & $P<0.01$ & n.s. \\
Males in Exp. 4 & $0.48 \pm 0.07$ & $0.40 \pm 0.02$ & $0.31 \pm 0.03$ & $0.26 \pm 0.03$ & $P<0.01$ & n.s. \\
\hline
\end{tabular}

Values are mean \pm s.e.m.

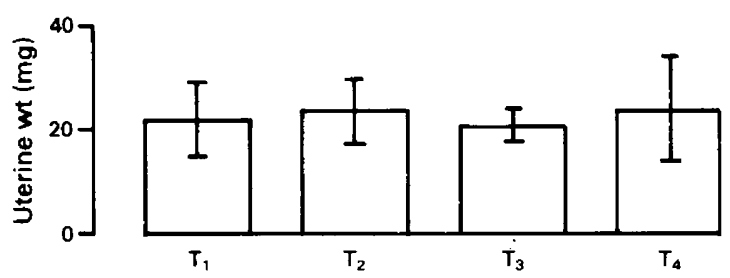

Fig. 2. Uterus weights (mean \pm s.e.m., 6 animals per treatment) for females in Exp. 2, exposed for 6 weeks to short photoperiods, and:

T1: separated from a mature male by a wire mesh barrier;

T2: separated from a mature male by a double wire mesh barrier;

T3: separated from a mature male by a solid metal sheet;

T4: reared in bedding that had previously been soiled by mature male voles.

\section{Experiment 3: the effect of castrated males on female maturation}

The females reared in the presence of a sexually mature male $(\mathrm{SP}+\delta)$ had significantly heavier uteri $(42.0 \pm 9.4 \mathrm{mg})$ than did those reared in the presence of a castrated male $(\mathrm{SP}+\$)$ $(10.8+3.5 \mathrm{mg} ; P<0.01)$. The ovaries $(4.33 \pm 0.50$ compared to $3.02 \pm 0.25 \mathrm{mg})$ and pituitary glands $(1.32 \pm 0.05$ compared to $0.92 \pm 0.07 \mathrm{mg})$ were likewise significantly larger in the SP $+\sigma^{*}$ treatment than in the SP $+\downarrow$ treatment $(P<0.05$ and $P<0.01$ respectively).

Uteri of females in the SP $+\delta$ treatment were heavier than those in the corresponding treatment in Exp. 1, and than those in all four treatments in Exp. 2. However, these differences were not statistically significant. The coefficient of variation for uterine weights $(61.9 \%$ for $\mathrm{SP}+\delta, 32 \cdot 2 \%$ for $\mathbf{S P}+\hat{Q})$ was, as in the corresponding treatments in Exps 1 and 2, high.

There was no statistically significant difference between the weights of uteri, ovaries or pituitary glands of the females in the SP $+\$$ treatment and those of females in the SP $-d$ treatment of Exp. 1.

There was no treatment effect on growth rates.

None of the females in Exps 1-3 had corpora lutea.

\section{Experiment 4: the effect of photoperiod and male presence on male maturation}

There was a significant effect of photoperiod on testis and seminal vesicle weight, and on seminiferous tubule diameter (all $P<0.001$ ), with animals in long photoperiod having heavier testes and seminal vesicles and wider seminiferous tubules than did animals in short photoperiods. Only tubule diameter showed a significant male effect $(P<0.05)$, with the tubules of those animals reared in the presence of mature males being narrower than those reared in their absence (see Table 3). There was no interaction between the photoperiod and the male effect. 
Table 3. Testis and seminal vesicle weights and seminiferous tubule widths for males in Exp. 4, exposed for 6 weeks to long (LP) or short (SP) photoperiods in the presence $\left(+\sigma^{*}\right)$ or absence $(-\delta)$ of a sexually mature male

\begin{tabular}{|c|c|c|c|c|c|c|}
\hline & \multicolumn{4}{|c|}{ Treatment } & \multirow{2}{*}{$\begin{array}{c}\text { Photoperiod } \\
\text { effect }\end{array}$} & \multirow{2}{*}{$\begin{array}{l}\text { Male } \\
\text { effect }\end{array}$} \\
\hline & $\mathbf{L P}+\hat{\sigma}$ & $\mathbf{L P}-\hat{A}$ & $\mathrm{SP}+\sigma$ & $\mathrm{SP}-\hat{\sigma}$ & & \\
\hline Wt of testes $(\mathrm{mg})$ & $436 \pm 55$ & $406 \pm 31$ & $43 \pm 7$ & $86 \pm 23$ & $P<0.001$ & n.s. \\
\hline vesicles (mg) & $232 \cdot 3 \pm 39 \cdot 4$ & $180 \cdot 1 \pm 28 \cdot 5$ & $3 \cdot 5 \pm 0 \cdot 2$ & $6 \cdot 3 \pm 2 \cdot 2$ & $P<0.001$ & n.s. \\
\hline Tubule width $(\mu \mathrm{m})$ & $187 \cdot 3 \pm 5 \cdot 1$ & $200 \cdot 2 \pm 4 \cdot 0$ & $84 \cdot 0 \pm 9 \cdot 4$ & $110 \cdot 8 \pm 13 \cdot 7$ & $P<0.001$ & $P<0.05$ \\
\hline
\end{tabular}

Values are mean \pm s.e.m.; 7 animals per treatment.

Growth rates were significantly higher in long than in short photoperiods $(P<0.01)$ but were not affected by the presence of a mature male (Table 2).

\section{Discussion}

The results of the present experiments show that the well-known effects of photoperiod upon the sexual development of female and male field voles can be modified by the presence of sexually mature males.

For females, long photoperiod stimulates ovarian, uterine and pituitary development, and this effect is augmented by the presence of a mature male. Short photoperiod inhibits or retards the growth of the ovaries, uterus and pituitary gland, but the presence of a mature male can, to some extent, overcome this effect. However, the greater variability in uterine weight that was found in animals in short photoperiod in the presence of a mature male suggests that there may be two types of female: those that are and those that are not sensitive to the presence of a mature male, in an otherwise inhibiting short photoperiod. The size of the uterus can be taken as a measure of oestrogen secretion (Zarrow, Yochim \& McCarthy, 1964). Increased uterine weight suggests higher oestrogen release from the ovaries which may enhance fertility through sexual arousal and by causing a stronger decidual cell reaction. Healthy virgin females from our laboratory stock are highly fertile at the age of 2 months, when uteri weigh about $40 \mathrm{mg}$ (Jorné-Safriel, 1968). Females with uteri of only 7-10 mg are unlikely to become pregnant.

It can be concluded that the stimulus provided by sexually mature males is pheromonal, since augmented uterine growth occurred in the short photoperiod in the absence of tactile or visual contact and even if females merely had contact with bedding previously used by mature males. Milligan $(1974,1975)$ found that, while tactile contact between male and female voles through a single barrier of wire mesh will cause a high proportion of females to ovulate, air-borne olfactory stimuli alone induce ovulation in a very much lower proportion of voles. The acceleration of puberty of females in the presence of mature males which has been reported for several other rodent species (Colby \& Vandenbergh, 1974; Carter, Getz, Gavish, McDermott \& Arnold, 1980; Baddloo \& Clulow, 1981; Marchlewska-Koj, 1984) has in most cases been effected by exposure of females to male urine. Attempts to isolate the active fraction of the urine have not yet been totally successful, but work on mouse urine (Marchlewska-Koj, 1981; Vandenbergh, 1983) suggests that the active part is associated with the protein fraction. When female mice are given direct contact with adult males, stimulation of sexual maturation is greater than when males are separated from the females, or when females are exposed to male-soiled bedding. This extra stimulation appears to occur via the tactile contact between the females and males. It also occurs if weanlings are exposed to androgenized females (Drickamer, 1974a). 
Castrated male field voles had no effect on the sexual development of the young females, as has been found for the laboratory and house mouse (Colby \& Vandenbergh, 1974; Bronson \& Maruniak, 1975). Castrated male mice regain their ability to accelerate puberty when testosterone propionate is administered, indicating that the inability of castrated males to stimulate female maturation is probably due to the absence of a male hormone-dependent pheromone (Lombardi, Vandenbergh \& Whitsett, 1976).

The failure to find recent corpora lutea in any of the females contrasts with other results in which female field voles in contact with adult males through a wire mesh barrier had several generations of corpora lutea, suggesting a sequence of ovulations (Milligan, 1974). However, there are differences of technique between the present experiments and those of Milligan (1974). Milligan (1974) used females which were adult at the start of the treatments and, as the sexually mature males to which they were exposed were confined to a wire mesh tunnel within the females' cage, tactile contact between the sexes would have been more extensive than in the present experiments. When Milligan used a double barrier, thus eliminating tactile contact, corpora lutea were present in only 1 female out of 20.

The effect of mature males on the rate of mauration of young male field voles was less straight forward. There was no influence on testis or seminal vesicle weight, but the width of the seminiferous tubules, a further index of testicular activity, was significantly smaller in the groups reared in the presence of adult males than in those reared in their absence, in long and short photoperiods. As wider seminiferous tubules in which normal spermatogenesis is progressing contain more germ cells, sexually mature males may adversely affect the fertility of young males. Vandenbergh (1971) also found with laboratory mice that sexually mature males inhibited development of young males, although in that case the presence of the adults reduced testis weight, but had no effect on seminiferous tubule width.

Growth rates of males and females were greater in long than in short photoperiods, but were unaffected by the presence of a mature male. The relationship between growth rate, gonadal activity and environmental stimuli (whether photoperiodic or pheromonal) seems not to be straight forward: an association between sexual maturation and growth rates has been reported for female mice and voles in response to various environmental factors (Cowley \& Wise, 1972; Batzli, Getz \& Hurley, 1977; Badloo \& Clulow, 1981), while in other cases no such association has been found (Vandenbergh, Drickamer \& Colby, 1972). It seems possible that gonadal hormones stimulate growth when their titre rises above a certain threshold, reached in these experiments in long photoperiods irrespective of the presence or absence of mature males. Dark \& Zucker (1984) showed that the increase in body weight of meadow voles (Microtus pennsylvanicus) associated with long photoperiods does not occur if the animals are castrated. Alternatively, it may be that the increased growth rates were regulated independently of the increase in the rate of sexual maturation via a stimulus provided only by photoperiod. Drickamer (1974b, 1975a), working on female house mice, showed that when sexual maturation of young females was delayed by pheromones produced by grouped females there was no effect on growth rates, but when constant light depressed the rate of sexual maturation to roughly the same extent, growth rates were also depressed.

The possibility of an interaction between photoperiod and male presence was tested in Exps 1 and 4 , but no such effect was found. The influences of male presence and of photoperiod on the sexual maturation are therefore factors that act independently of each other. Drickamer (1975b), working with female house mice, found no interaction between the inhibiting effect of constant light, the stimulating effect of male presence, and the inhibiting effect of grouping on sexual maturation (as indicated by age at first oestrus).

The present results have shown that a pheromonal influence from mature male field voles, by stimulating sexual development in young females and inhibiting it in young males, can modify the undoubted effect that photoperiod has on the development and maintenance of gonadal activity. This appears to distinguish the field vole, Microtus agrestis, from the prairie vole, Microtus ochrogaster, in which, under laboratory conditions, the sexual development and fertility of males is 
influenced by photoperiod but that of females is not, being regulated instead by the presence of sexually mature males (Nelson, 1985).

These various findings which show the importance of pheromones in stimulating or inhibiting gonadal activity have implications for wild populations of voles. For unknown reasons breeding seasons extend later into the autumn at some stages in the 4-year population cycles of microtine rodents than at others (Krebs, 1978). The existence of mature males when daylength is less than optimal for sexual development of the young (Baker \& Ransom, 1933) would help to sustain reproduction at least in some females. The presence of over-wintered adult males which become sexually mature early in the new breeding season (Chitty, 1952) would augment the rate of sexual maturation of the young females arising from the first pregnancies of spring, and tend to retard the sexual development of young males. This, from an evolutionary point of view, would be advantageous for the mature males.

N.S. was supported by a Natural Environmental Research Council Research Studentship. We thank Janet Evans and Valerie Petts for invaluable assistance with this work.

\section{References}

Baddloo, E.G.Y. \& Clulow, F.V. (1981) Effects of the male on the growth, sexual maturation and ovulation of young meadow voles, Microtus pennsylvanicus. Can. J. Zool. 59, 415-421.

Bailey, N.T.J. (1981) Statistical Methods in Biology. Hodder \& Stoughton, London.

Baker, J.B. \& Clarke, J.R. (1986) The field vole (Microtus agrestis) and the bank vole (Clethrionomys glareolus). In UFAW Handbook on the Care and Management of Laboratory Animals. Ed. T. B. Poole. Churchill Livingstone, Edinburgh (In Press).

Baker, J.R. \& Ransom, R.M. (1933) Factors affecting the breeding season of the field mouse (Microtus agrestis). Part III. Locality. Proc. R. Soc. B. 113, 486 495.

Batzli, G.O., Getz, L.L. \& Hurley, S.S. (1977) Suppression of growth and reproduction of microtine rodents by social factors. J. Mammal. 58, 583-591.

Bronson, F.H. \& Maruniak, J.A. (1975) Male-induced puberty in female mice: evidence for a synergistic action of social cues. Biol. Reprod. 13, 9498.

Carter, C.S., Getz, L.L., Gavish, L., McDermott, J.L. \& Arnold, P. (1980) Male-related pheromones and the activation of female reproduction in the prairie vole (Microtus ochrogaster). Biol. Reprod. 23, $1038-1045$.

Chitty, D. (1952) Mortality amongst voles (Microtus agrestis) at Lake Vyrnwy, Montgomeryshire in 1936-1939. Phil. Trans. R. Soc. 236, 505-552.

Clarke, J.R. (1981) Physiological problems of seasonal breeding in eutherian mammals. Oxford Rev. Reprod. Biol. 3, 244-312.

Clarke, J.R. \& Clulow, F.V. (1973) The effect of successive matings upon bank vole (Clethrionomys glareolus) and vole (Microtus agrestis) ovaries. In The Development and Maturation of the Ovary and its Function, pp. 160-170. Ed. H. Peters. Excerpta Medica (Int. Congr. Ser. No. 267), Amsterdam.

Clarke, J.R. \& Kennedy, J.P. (1967) Effect of light and temperature upon gonadal activity in the vole (Microtus agrestis). Gen. comp. Endocr. 8, 474-488.
Colby, D.R. \& Vandenbergh, J.G. (1974) Regulatory effect of urinary pheromones on puberty in mice. Biol. Reprod. 11, 268-279.

Cowley, J.J. \& Wise, D.R. (1972) Some effects of mouse urine on neonatal growth and reproduction. Anim. Behav. 20, 499-506.

Dark, J. \& Zucker, I. (1984) Gonadal and photoperiodic control of seasonal body weight changes in male voles. Am. J. Physiol. 247, R84-R88.

Drickamer, L.C. (1974a) Contact stimulation, androgenised females and accelerated sexual maturation in female mice. Behav. Biol. 12, 101-110.

Drickamer, L.C. (1974b) Sexual maturation of female house mouse: social inhibition. Devl Psychobiol. 73, 257-265.

Drickamer, L.C. (1975a) Daylength and sexual maturation in female house mice. Devl Psychobiol. 8, $561-570$.

Drickamer, L.C. (1975b) Female mouse maturation: relative importance of social factors and daylength. J. Reprod. Fert. 44, 147-150.

Grocock, C.A. (1972) The influence of some environmental factors on the testis of the vole, with particular reference to spermatogenesis. D.Phil. thesis, University of Oxford.

Grocock, C.A. \& Clarke, J.R. (1974) Photoperiodic control of testis activity in the vole, Microtus agrestis. J. Reprod. Fert. 39, 337-347.

Gustafsson, T.A. (1983) Reproduction and social regulation of sexual maturation in relation to population cyclicity in bank voles, Clethrionomys glareolus. Doctoral dissertation, Lund University, Sweden.

Jorne-Safriel, O. (1968) Some factors affecting the adrenal juxtamedullary zone in the vole (Microtus agrestis) and bank vole (Clethrionomys glareolus). D.Phil. thesis, University of Oxford.

Lombardi, J.R., Vandenbergh, J.G. \& Whitsett, J.M., (1976) Androgen control of the sexual maturation pheromone in house mouse urine. Biol. Reprod. 15, 179-186. 
Krebs, C.J. (1978) A review of the Chitty hypothesis of population regulation. Can. J. Zool. 56, 2463-2480.

Marchlewska-Koj, A. (1981) Pregnancy block elicited by male urinary peptides in mice. J. Reprod. Fert. 61, 221-224.

Marchlewska-Koj, A. (1984) Pheromones and mammalian reproduction. Oxford Rev. Reprod. Biol. 6, 266-302.

Milligan, S.R. (1974) Social environment and ovulation in the vole, Microtus agrestis. J. Reprod. Fert. 41, 35-37.

Milligan, S.R. (1975) Mating, ovulation and corpus luteum function in the vole, Microtus agrestis. $J$. Reprod. Fert. 42, 35-44.

Nelson, R.J. (1985) Photoperiod influences reproduction in the prairie vole (Microtus ochrogaster). Biol. Reprod. 33, 596-602.
Vandenbergh, J.G. (1971) The influence of the social environment on sexual maturation in male mice. $J$. Reprod. Fert. 24, 383-390.

Vandenbergh, J.G. (1983) Pheromonal regulation of puberty. In Pheromones and Reproduction in Mammals, pp. 95-112. Ed. J. G. Vandenbergh. Academic Press, New York.

Vandenbergh, J.G., Drickamer, L.C. \& Colby, D.R. (1972) Social and dietary factors in the sexual maturation of mice. J. Reprod. Fert. 28, 397-406.

Zarrow, M.X., Yochim, J.M. \& McCarthy, J.L. (1964) Experimental Endocrinology. A Sourcebook of Basic Techniques. Academic Press, New York \& London.

Received 23 January 1986 